\title{
Longitudinal Study of Entering Students with Engineering as Their Major: Retention and Academic Success
}

\section{Prof. Cathy W. Hall, East Carolina University}

Cathy Hall is a professor in the Department of Psychology at East Carolina University. She holds a Bachelor's in Psychology from Emory University, and a MEd and PhD in Educational Psychology from the University of Georgia. Her expertise includes psychological assessments, research design and methodology, and data analysis. Her research interests include emotional intelligence, metacognition, resilience, and self-regulation.

Karen A. De Urquidi, East Carolina University

Dr. Paul J. Kauffmann P.E., East Carolina University

Paul J. Kauffmann is a professor in the Department of Engineering at East Carolina University. His industrial career included positions as Plant Manager and Engineering Director. Dr. Kauffmann received a BS degree in Electrical Engineering and MENG in Mechanical Engineering from Virginia Tech. He received his Ph.D. in Industrial Engineering from Penn State and is a registered Professional Engineer in Virginia and North Carolina.

\section{Prof. Karl Louis Wuensch, East Carolina University}

Karl L. Wuensch is a full professor in the Department of Psychology at East Carolina University. In addition to teaching the three graduate courses in statistics and research design offered by the department, he also teaches a couple of undergraduate courses each year. He has been recognized as a Teacher/Scholar by the university and has received the Board of Governors' Award for Excellence in Teaching, the highest teaching award in the University of North Carolina system. He has published 75 articles in scholarly journals and eight chapters in books.

\section{Dr. William Swart, East Carolina University}

William Swart is professor of Marketing and Supply Chain Management at East Carolina University. He holds a Ph.D. in Operations Research and a M.S. in Industrial and Systems Engineering from the Georgia Institute of Technology and a B.S. in Industrial Engineering with Honors from Clemson University. Dr. Swart's experience is diversified between industry and academia. In academia, he served as Provost and Vice Chancellor for Academic Affairs at East Carolina University, Dean of Engineering at New Jersey Institute of Technology and Old Dominion University, Associate Dean of Business and Economics at California State University, Chairman of the Department of Industrial Engineering and Management Systems at the University of Central Florida. In industry, he served as Vice President for Operations Systems and Vice President for Management Information Systems at Burger King Corporation.

Dr. Swart's professional achievements have been recognized by the Institute of Industrial Engineers with the 1994 Operations Research Practice Award. He was awarded the Achievement in Operations Research Medal from the Institute for Operation Research and Management Sciences (INFORMS) and has been named an Edelman Laureate for twice having been a finalist in the prestigious Edelman Competition for the best Operations Research application in the world. He has over 100 scholarly publications and has been Principal or Co-Principal Investigator for grants and contracts in excess of \$10 million.

\section{Dr. Odis Hayden Griffin Jr., East Carolina University}

Hayden Griffin is currently Professor and Chair of the Department of Engineering at East Carolina University and Professor Emeritus of Engineering Education at Virginia Tech. He holds BS and MS in Mechanical Engineering from Texas Tech and $\mathrm{PhD}$ in Engineering Mechanics from Virginia Tech. He has done work in student learning, academic program development, and the use of technology in the curriculum. He is a registered professional engineer in Virginia. 


\title{
Longitudinal Study of Engineering Majors: Retention and Academic Success
}

\begin{abstract}
This paper presents the results of a longitudinal study assessing the role of math readiness and personality factors in retaining undergraduate students in an engineering program. Participants are freshmen enrolled in an entry level engineering course who were asked to complete a set of surveys that included affective and meta cognitive measures. They were then followed throughout their academic career through graduation, major change, or leaving the university. These students were also administered a calculus readiness test (Assessment and LEarning in Knowledge Spaces -ALEKS) as part of their entry into engineering. While not all students have completed their degree at this time, our study assesses the status of these students as they have progressed through their academic career.
\end{abstract}

The paper explores the hypothesis that engineering retention is related not only to basic aptitude but also affective factors. In the study, aptitude was measured by SAT Verbal and Math scores, high school GPA, and the ALEKS assessment of calculus readiness. Affective factors were assessed by the NEO Five Factor Inventory and the Nowicki-Duke Locus of Control scale. Binary logistic regression was employed to determine if these measures are predictive of retention during the course of these students' academic career. The study found that the most significant aptitude predictors of retention are SAT math and the ALEKs calculus readiness score while conscientiousness is the most important of the affective factors.

\section{Introduction}

Retention and overall recruitment of engineering students is a continuing concern among university academic programs and workforce planners nationwide since it is anticipated engineering and science fields will grow at more than three times the rate of other professions. ${ }^{1}$ A recent analysis found that while engineering graduates often have a high rate of persistence (93\% of those completing eight semesters entered college with engineering as their stated major), engineering programs also have $50 \%$ or more of entering students migrating to other majors. ${ }^{2}$ In improving retention, engineering educators have spent significant effort in identifying relationships between various measures of success and prediction variables. In this way, it may be possible to identify targeted interventions to improve success or prevent failure. As a result of these efforts, a variety of multi-variable models have been developed to predict various measures of student success using a range factors.

The range of studied success factors is wide. For example, Takahira et al. ${ }^{3}$ found that the primary factors associated with persistence in an engineering statics course (a perceived gate keeper for engineering success) were GPA and SAT-math scores. Another study reported a positive effect of an entrepreneurship program on GPA and retention. ${ }^{4}$ Other researchers found scores from a non-technical, writing assignment was a predictor of academic success of freshmen engineering students as measured by cumulative grade point average after completion of the first 
two semesters. ${ }^{5}$ Another study identified poor teaching and advising, curriculum difficulty, and lack of belonging as the three most influential factors in decisions to transfer from engineering. ${ }^{1}$

Other models have been more complex and varied. For example, student success and persistence were examined by French et al. ${ }^{6}$ using hierarchical linear regression. They examined both quantitative variables (SAT scores, high school rank, university cumulative grade point average) and qualitative variables (such as academic motivation and institutional integration). For measures of success they used junior and senior GPA, university enrollment and major enrollment over six and eight semesters. The study found that SAT scores, high school rank, and gender were significant predictors of GPA and that an orientation course was ineffective.

It appears that a single success prediction model may not be applicable across engineering programs. Zhang et al. ${ }^{7}$ evaluated a number of factors and their impact on engineering student success as measured by graduation rate. Using a multiple logistic regression model and data from nine institutions, they examined the impact on college graduation of high school GPA, gender, ethnicity, quantitative and verbal SAT scores, and citizenship. The study reports that high school GPA and quantitative SAT score were the only significant factors for all models tested and the significance of other predictors varied among institutions.

Another study ${ }^{8}$ examined two frequently used selection variables, high school GPA and ACT composite test score, as predictors of college graduation success in a minority engineering program. It found that the only significant predictor of engineering graduation was high school GPA. Both high school GPA and ACT scores were predictors of college GPA but only high school GPA was a predictor of graduation in engineering.

Studies have also examined cognitive and psychological variables. An early example assessed predictors of the freshmen GPA of 70 college women with higher predicted GPA. For women with higher GPA, both high school GPA and academic self-concept formed a strong model that predicted $56 \%$ of the variance in GPA. For college women with lower predicted GPAs, the factors of internal locus of control and amount of effort put into work accounted for $46 \%$ of the variance. $^{9}$ An example of a recent study in this area examined the role of learning types and study skill measures to predict success. ${ }^{10}$ This study found that these measures did relate to GPA as students progressed through an engineering degree program.

Cognitive and personality factors have also been explored in relation to time to degree. ${ }^{11}$ Data collected over a six-year period showed a specific psychological characteristic (locus of control) significantly contributed to obtaining an undergraduate degree in a timely manner. Along with this, meta cognitive skills, action behaviors related to academic success, and high school GPA were the three factors that emerged as predictors of college GPA. This research supported Borkowski's ${ }^{12,13}$ model of academic achievement based on the dimensions of meta cognition and affective factors. Meta cognition involves knowledge of learning strategies and using these strategies in an effective and efficient manner. The affective component involves factors such as self-efficacy, motivation, and locus of control. Research supports the role of meta cognitive strategies as a direct influence of academic success as measured by GPA, but internal control also plays an indirect role. 
The objective of this study was to complement this literature by more closely examining performance contributors which affect success in the first two years of engineering study. Generally, student success or failure in this time interval results in changes in major or withdrawal from the university; the actions that result in retention failures for the engineering degree. Consequently, the primary focus of this study was to determine which variables can predict freshmen and sophomore retention. In particular, we explore in more detail the interplay and importance of aptitude measures and affective personality factors. With a better understanding of the relationship of these two domains, program faculty can identify appropriate interventions to improve retention. The next section provides background information about the study and our research objectives.

\section{Study Background}

In addition to adding to the literature noted above, another key objective of our particular study focuses on enhancing our ability to identify the applicants in the admissions process with improved likelihood of success. As a relatively new program, it is critical for us to better understand our student population and how it mirrors (or not) national studies. The most direct goal for our work is to improve and validate our admissions model. From a practical and human perspective, this goal leads to other sub goals revolving primarily around improved retention but also addressing issues such as these:

- Our program should provide access to an engineering career within the constraints of quality and performance. A significant percentage of our students come from high schools in relatively poor communities and they often do not have the same opportunities for advanced mathematics courses. How do we better identify and support students who can succeed?

- Many of our students are first generation college students and come from households with limited financial resources. Consequently, we want to avoid, to the extent possible, student loan debt incurred during semesters pursuing an engineering degree without success.

Two of our previous studies examined our retention and admissions system. The first applied stepwise regression to identify the most significant factors to predict undergraduate grade point average at the end of the freshman and sophomore years. ${ }^{14}$ This model examined standardized test scores, rank in high school class, and various measures of high school grade point average for three different years of performance. We were limited to three years of data at the time of this study since we had admitted our first students in fall 2004. The results, for this sample of first and second year students, showed unweighted high school grade point average and rank in high school graduating class were the most important predictors of college grade point average. Standardized test scores were not significant predictors.

Our second study occurred a year later and employed a linear regression model to examine the influence of personality indicators on grade point success for engineering students. ${ }^{15}$ This study employed two measurement tools for personality indicators. The first is commonly called the Big Five personality indicator. Psychologists define the "Big Five" personality traits as broad factors or dimensions of personality, discovered through empirical studies. ${ }^{16}$ These factors are often defined as follows: ${ }^{17}$ 
- Extraversion (sometimes called Surgency). This broad dimension encompasses specific traits such as being talkative, energetic, and assertive.

- Agreeableness. This dimension includes traits like sympathetic, kind, and affectionate.

- Conscientiousness. People high in this trait tend to be organized, thorough, and planning oriented.

- Neuroticism (sometimes reversed and called Emotional Stability). Neuroticism is characterized by traits like tension, moodiness, and anxiety.

- Openness to Experience (sometimes called Intellect or Intellect/Imagination). This dimension includes having wide interests and being imaginative and insightful.

The second personality indicator employed in this study was the locus of control (LOC) test. Rotter $^{18}$ is credited with the original locus of control concept which reflects a generalized belief concerning who or what influences events from internal to external control: Internal control describes the belief that control of future outcomes resides primarily in oneself. On the other hand, external control refers to the expectancy that control is outside of oneself, either in the hands of powerful other people or due to fate/chance. In the context of engineering education, an internal locus of control would describe a student who believes he/ she is capable of controlling future success by hard work, study, attendance, and similar efforts. On the other hand, a student with an external locus of control believes that study and class attendance may be outweighed by the random chance of the wrong questions appearing on a test. The Nowicki-Duke Locus of Control Scale ${ }^{19}$ was used to assess internal versus external attributions. The scale consists of forty yes or no items that are summed to indicate the respondent's perceptions of external control. Higher scores indicate a more external locus of control whereas lower scores indicate a more internal locus of control.

The results of this first study showed conscientiousness in the big five model was a significant factor in a multi variable, linear model predicting grade point average. However the analysis indicated other prediction factors should be explored to complement conscientiousness in the model. LOC was also a significant predictor and the most promising two factor model combined LOC and conscientiousness from the big five model. Consequently we developed a plan for a longitudinal study which would further explore these findings. The next section describes the methodology for the study and the results thus far.

\section{Study Methodology}

This section examines the current results of our ongoing study. It begins with an overview of the participants, and then reviews the procedure, and instruments used.

\section{Participants}

The 277 participants in this study (241 men and 36 women) were engineering freshman who were enrolled in a one credit hour introductory course in engineering (currently ENGR 1000). Entering freshman were recruited from the introductory course in fall semesters from 2007 to 2010 and asked to participate in a longitudinal study specific to retention in the engineering program. Out of a possible 302 students, 25 did not participate. At the time of the study, ENGR 1000 was not a required course and so not all entering engineering freshman were enrolled (169 students did not have the opportunity to participate, 156 men and 13 women). Consequently, the 
participants in this study do not reflect the entire entering class nor do they include transfer students or students migrating to engineering from other majors. Race/ethnicity for the participants was as follows: Native American - 2 (0.7\%); African American - 29 (10.5\%); Pacific Islander - $1(0.4 \%)$; Asian 16 (5.8\%); Hispanic/Latino - 8 (2.9\%); Caucasian - 205 (74.0\%); Other $-14(5.1 \%)$ and 2 did not indicate race/ethnicity.

\section{Procedure}

Participants were recruited from ENGR 1000, a course designed specifically for entering engineering students. The course provided an opportunity for students to meet peers with the same declared major and learn more about different fields open to engineering majors, and build success skills. As noted, participants were recruited from this engineering seminar fall semesters for the years 2007 through 2010 .

Participation was voluntary and if a student chose not to participate, it did not negatively influence his/her standing in either the course or the engineering program. The students who agreed to participate were asked to sign a consent form allowing permission for the researchers to access their SAT scores (Verbal and Mathematics), calculus readiness test scores as measured by the ALEKS test, ${ }^{20}$ and both their high school and college GPAs as part of the study. Next, students were asked to complete a series of self-report questionnaires including basic demographic information (i.e., gender, age, classification, and ethnic origin), the NEO-FF ${ }^{21}$ for the five factor evaluation, and the ND- $\mathrm{LOC}^{19}$ for the LOC evaluation. Administration of the assessment battery took approximately 60 minutes. Appropriate institutional review approvals were obtained and American Psychological Association (APA) ethical guidelines for research with human participants were followed.

\section{Instruments}

This section briefly summarizes the measurement instruments employed in this study:

Assessment and Learning in Knowledge Spaces (ALEKS). ${ }^{20}$ The focus of the ALEKS test employed was calculus readiness exam used by the engineering program as a means of measuring students' mathematical readiness for college level calculus. Scores from the ALEKS are used to determine if a student has the prerequisite knowledge to be placed in college calculus in the fall of their freshman year. For admission into East Carolina University's engineering program, each student was administered the ALEKS test during the summer before beginning college in the fall.

The Scholastic Aptitude Test (SAT). SAT scores are part of students' applications to the university where this study took place, and students' scores were obtained from admission records. While the SAT has undergone substantial modification since its inception, it still remains one of the primary assessment instruments used in college admission. ${ }^{22}$ The SAT has been used by universities as a way of determining who would be more likely to succeed in the university setting ${ }^{20}$ and is also related to general aptitude and has served as an estimate of aptitude for conducting research with college students. ${ }^{21}$

Nowicki-Duke Locus of Control Scale (ND-LOC). The ND-LOC measures locus of control in adolescents and young adults. ${ }^{24}$ The scale is a 40 item assessment that asks how a person feels 
during different life experiences, such as "Do you believe wishing can make good things happen?" Each question is answered by marking a yes or no, and a point is assigned for every yes answer. A high score on the assessment is associated with high levels of external LOC.

NEO Personality Inventory - FFI (NEO-FFI). The NEO-FFI is a personality assessment of five major personality factors: Neuroticism, Extraversion, Openness, Agreeableness, and Conscientiousness. ${ }^{25}$ Each question is rated on a five-point Likert scale ranging from strongly agree to strongly disagree.

\section{Results}

As a starting point, since the participants in the longitudinal study did not reflect all entering freshman, it was important to determine if the two groups (participants vs. non-participants) differed from one another in any significant manner. A series of analyses of variance was performed comparing participant vs. non-participant on mean SATM, SATV, high school GPA and ALEKS. There were no significant differences between the two groups for MSAT $[F(1$, $428)=0.44, p=0.51]$, high school GPA $[F(1,432)=2.27, p=0.13]$ or scores on the ALEKS $[F(1,392)=0.11, p=0.74]$. However, there was a significant difference between the two groups for VSAT $[F(1,428)=4.38, p=0.03]$. The non-participant group had higher VSAT than the participant group ( $M=508.65, S D=74.66$ and $M=494.67, S D=61.52$, respectively).

Of the 277 entering engineering freshman taking the ENGR 1000 course, $166(59.92 \%)$ left the program. When student records were analyzed, 91 of those leaving (54.8\%) left in "good standing" meaning that they had a GPA of at least a 2.0. Ten of these students transferred to another university. The remaining 81 students in good standing migrated to other majors within the institution. Seventy-five students $(45.2 \%)$ of those leaving left in poor standing (GPA below 2.0) with 30 of these students failing out of the engineering program. There were 111 students (96 men and 13 women) who persisted in engineering. The majority of students leaving engineering did so their first year $-124(75.0 \%)$. Thirty-six $(21.69 \%)$ students left during the second year. If students persisted beyond their second year there was a very low rate of leaving engineering with only 6 students (3.6\%) choosing to leave after this time. Consequently, we defined persistence as the completion of the first four semesters in good standing.

Table 1 presents the correlations, means and standard deviations for the MSAT, VSAT, ALEKS, HSGPA and personality factors based on persistence. As noted earlier, the ALEKS score is based on a 0 to 100 point scale, GPA for college and high school is on a scale of 0.00 to 4.0, while the SAT Verbal and Math are based on minimum of 200 and maximum 800 points for each.

Relative to quantitative skills, Table 1 shows engineering program persistence was significantly correlated with MSAT, HSGPA, and ALEKS. There is a significant relationship between persisting in the program and entering math skills (ALEKS and SATM) and how well students performed as measured by HSGPA in their high school curricula. In terms of personality variables, there were significant correlations between conscientiousness and persistence as well as neuroticism and persistence (we hypothesize that neuroticism may be the student who cannot let go of a problem until solved). Those students who were higher on these two measures were 
more likely to persist. None of the other personality variables or the LOC demonstrated a significant relationship with persistence in the engineering program.

Table 1: Correlations in Study Variables $(n=277$, Bold Indicates Significant at 99\%)

\begin{tabular}{|c|c|c|c|c|c|c|c|c|c|c|c|c|}
\hline Factor & 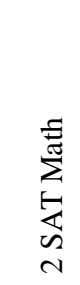 & 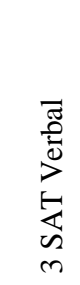 & 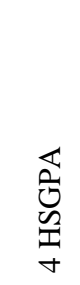 & $\begin{array}{l}\frac{\pi}{2} \\
\frac{1}{2} \\
\text { 究 }\end{array}$ & 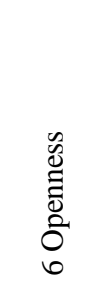 & 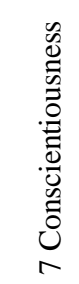 & 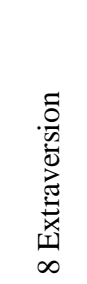 & 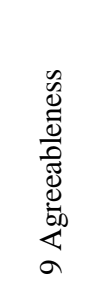 & 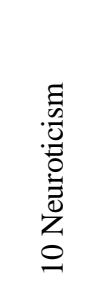 & 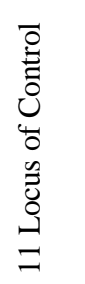 & 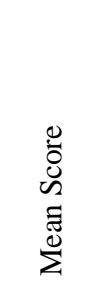 & 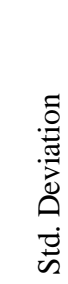 \\
\hline $\begin{array}{l}\text { 1 Persistence } \\
\text { (success in } \\
\text { exceeding } 4 \\
\text { semesters) }\end{array}$ & $\begin{array}{l}\mathbf{0 . 2 3} \\
* *\end{array}$ & 0.02 & $\begin{array}{l}0.21 \\
* *\end{array}$ & $\begin{array}{l}\mathbf{0 . 2 6} \\
* *\end{array}$ & 0.07 & $\begin{array}{l}\mathbf{0 . 2 2} \\
* *\end{array}$ & 0.07 & 0.12 & $\begin{array}{l}\mathbf{0 . 1 8} \\
* *\end{array}$ & 0.04 & & \\
\hline 2 SAT Math & & $\begin{array}{l}\mathbf{0 . 4 4} \\
* *\end{array}$ & $\begin{array}{l}0.13 \\
*\end{array}$ & $\begin{array}{l}\mathbf{0 . 4 2} \\
* *\end{array}$ & $\begin{array}{l}0.13 \\
*\end{array}$ & 0.11 & 0.07 & 0.02 & $\begin{array}{l}0.12 \\
*\end{array}$ & 0.09 & 565.3 & 63.8 \\
\hline 3 SAT Verbal & & & 0.07 & 0.08 & $\begin{array}{l}\mathbf{0 . 1 3} \\
* *\end{array}$ & -.001 & 0.01 & -0.07 & -0.20 & -0.09 & 489.7 & 73.5 \\
\hline 4 HSGPA & & & & $\begin{array}{l}0.12 \\
*\end{array}$ & 0.01 & 0.10 & -0.01 & 0.05 & 0.08 & 0.02 & 3.11 & 0.36 \\
\hline 5 ALEKS & & & & & -0.02 & $\begin{array}{l}\mathbf{0 . 1 8} \\
* *\end{array}$ & 0.05 & 0.02 & $\begin{array}{l}0.15 \\
*\end{array}$ & 0.07 & 53.7 & 19.1 \\
\hline 6 Openness & & & & & & $\begin{array}{l}\mathbf{0 . 3 3} \\
* *\end{array}$ & $\begin{array}{l}\mathbf{0 . 3 2} \\
* *\end{array}$ & $\begin{array}{l}\mathbf{0 . 2 1} \\
* *\end{array}$ & $\begin{array}{l}\mathbf{0 . 3 5} \\
* *\end{array}$ & $\begin{array}{l}0.15 \\
*\end{array}$ & 26.7 & 6.1 \\
\hline 7 Conscientious & & & & & & & $\begin{array}{l}\mathbf{0 . 4 3} \\
* *\end{array}$ & $\begin{array}{l}\text { 0.40 } \\
* *\end{array}$ & $\begin{array}{l}\mathbf{0 . 4 3} \\
* *\end{array}$ & 0.11 & 31.4 & 7.2 \\
\hline 8 Extraversion & & & & & & & & $\begin{array}{l}\mathbf{0 . 4 1} \\
* *\end{array}$ & $\begin{array}{l}\mathbf{0 . 2 2} \\
* *\end{array}$ & $\begin{array}{l}0.15 \\
*\end{array}$ & 30.6 & 6.4 \\
\hline 9 Agreeableness & & & & & & & & & $\begin{array}{l}\mathbf{0 . 1 6} \\
* *\end{array}$ & $\begin{array}{l}0.13 \\
*\end{array}$ & 28.9 & 5.4 \\
\hline 10 Neuroticism & & & & & & & & & & $\begin{array}{l}\mathbf{0 . 4 5} \\
* *\end{array}$ & 25.8 & 5.4 \\
\hline $\begin{array}{l}11 \text { LOC- Locus of } \\
\text { control }\end{array}$ & & & & & & & & & & & 13.8 & 6.0 \\
\hline
\end{tabular}

Notes: SAT = Scholastic Aptitude Test, HSGPA = high school grade point average, ALEKS = Assessment and Learning in Knowledge Spaces; LOC = Nowicki-Duke Locus of Control Scale; and the NEO Five Factor Inventory Scales for Openness, Conscientiousness, Extraversion, Agreeableness, and Neuroticism.

$* p<0.05, * * p<0.01$.

A forward sequential binary logistic regression was performed next with the predicted event being persistence in the engineering program. The predictors were entered starting with trait variables (i.e., personality): 1) NEO-FF personality factors and 2) ND-LOC. Measures of aptitude were entered next: 3) ALEKS; 4) MSAT and VSAT; and 5) high school GPA. Equation 1 describes the general equation structure for the multiple binary model where the $\beta_{\mathrm{i}}$ are the multipliers of the predictor variable observations $\left(\mathrm{x}_{\mathrm{i}}\right)$ and $\pi_{\mathrm{i}}$ are the observed proportions.

$$
\pi_{i}=\frac{e^{\left(\beta_{o}+\beta_{1} X_{1 i}+\beta_{2} X_{2 i}+\ldots+\beta_{k} X_{k i}\right)}}{1+e^{\left(\beta_{o}+\beta_{1} X_{i}+\beta_{2} X_{2 i}+\ldots+\beta_{k} X_{k i}\right)}}
$$

Equation 1 
Table 2 presents the results of this binary logistic regression analysis using the maximum likelihood estimator method. Columns in Table 2 represent:

- $\quad$ B: the fitted multipliers $\left(\beta_{i}\right)$ for the observed criterion variable values for each predictor at each step.

- OR: the odds ratio which is equal to $\exp (\mathrm{B})$, also written $\mathrm{e}^{\mathrm{B}}$. This is the multiplicative amount by which the odds of non-persistence change per 1 point of change in the predictor, after the remaining predictors in the model at that step are held constant. For example, the 0.959 odds ratio for conscientiousness in step 1 indicates that the odds of non-persistence are multiplicatively lowered by 0.959 with each one point increase in a respondent's conscientiousness score.

- $\quad$-2LL and $\Delta$-2LL: These values are relative badness-of-fit indicators, that is, large numbers mean poorer fit of the model to the data. Typically analytical software begins with the intercept only value and then recalculates this as variables enter the model. This is a baseline number indicating model fit. This number has no direct analog in linear regression. In our case for step 1, we reduced the -2LL value by 15.74 to 329.32 and improved the model by adding the NEO -FFI predictors. Similarly, we did not significantly improve this statistic for Step 2 and that is a primary reason why this model was evaluated as insignificant in the overall $p$ value $(0.717)$.

- The unique contribution of each predictor is evaluated by the Wald $\chi^{2}$, in the context of the other predictors, that is, holding constant the other predictors and eliminating any overlap between the predictors.

Prior to entering any predictors, the persistence of entering college students was $40.2 \%$, and nonpersistence was $59.8 \%$ as indicated by the basic data base. Steps in the Table 2 model are noted below:

- Based on the regression analysis, step 1 shows entry of the NEO-FF subscales was statistically significant with the overall percentage of correct classifications at $64.1 \%$. Conscientiousness was the only personality factor that reached significance at $p=0.031$.

- Step 2 entry of LOC did not significantly increase the fit of model to data, as indicated by the $p$ value of 0.717 . The overall percentage of correct classifications following this entry dropped to $63.7 \%$. Conscientiousness was still the best predictor at $p=0.038$.

- Step 3 entry of ALEKS produced a statistically significant increase in fit at $p<0.001$ and the overall percentage of correct classifications was $66.4 \%$. ALEKS was the most significant factor at $p<0.001$.

- Step 4 entry of MSAT and VSAT also produced a significant increase in fit, with the overall percentage of correct classifications at 67.2\%. ALEKS and MSAT were significant at $p=0.019$ and $p=0.017$ respectively.

- Step 5 entry of HSGPA produced a statistically significant increase in fit $(p=0.003)$, with the percentage of correct classifications at $69.5 \%$ (51.5\% for persistence and $81.7 \%$ for non-persistence). The most significant factors in the model were ALEKS $(p=0.029)$, $\operatorname{MSAT}(p=0.02)$, and HSGPA $(p=0.004)$. 
Table 2: Sequential Binary Logistic Regression Predicting Retention in the Engineering Program

\begin{tabular}{|c|c|c|c|c|c|c|c|}
\hline Variables & B & OR & $-2 \mathrm{LL}$ & $\Delta-2 \mathrm{LL}$ & Wald $\chi^{2}$ & $\mathrm{p}$ & $\%$ Correct \\
\hline $\begin{array}{c}\text { Step 1 } \\
\text { NEO-FFI } \\
\text { Openness } \\
\text { Conscientiousness } \\
\text { Extraversion } \\
\text { Agreeableness } \\
\text { Neuroticism }\end{array}$ & $\begin{array}{c}0.022 \\
-0.053 \\
0.024 \\
-0.024 \\
-0.026\end{array}$ & $\begin{array}{l}1.022 \\
0.959 \\
1.024 \\
0.976 \\
0.975\end{array}$ & 329.323 & 15.740 & $\begin{array}{l}0.751 \\
4.646 \\
0.876 \\
0.750 \\
3.667\end{array}$ & $\begin{array}{c}0.008 * * \\
0.386 \\
0.031 * \\
0.349 \\
0.386 \\
0.055\end{array}$ & 64.1 \\
\hline $\begin{array}{c}\text { Step 2 } \\
\text { NEO-FFI } \\
\text { Openness } \\
\text { Conscientiousness } \\
\text { Extraversion } \\
\text { Agreeableness } \\
\text { Neuroticism } \\
\text { LOC }\end{array}$ & $\begin{array}{c}0.022 \\
-0.051 \\
0.023 \\
-0.026 \\
-0.028 \\
0.009\end{array}$ & $\begin{array}{l}1.022 \\
0.950 \\
1.024 \\
0.975 \\
0.972 \\
1.009\end{array}$ & 329.192 & 0.131 & $\begin{array}{l}0.756 \\
4.316 \\
0.825 \\
0.818 \\
3.501 \\
0.131\end{array}$ & $\begin{array}{c}0.717 \\
\\
0.385 \\
0.038^{*} \\
0.364 \\
0.366 \\
0.061 \\
0.717\end{array}$ & 63.7 \\
\hline $\begin{array}{c}\text { Step } 3 \\
\text { NEO-FFI } \\
\text { Openness } \\
\text { Conscientiousness } \\
\text { Extraversion } \\
\text { Agreeableness } \\
\text { Neuroticism } \\
\text { LOC } \\
\text { ALEKS } \\
\end{array}$ & $\begin{array}{c}0.012 \\
-0.042 \\
0.023 \\
-0.031 \\
-0.024 \\
0.012 \\
-0.026 \\
\end{array}$ & $\begin{array}{l}1.012 \\
0.959 \\
1.023 \\
0.969 \\
0.977 \\
1.009 \\
0.974 \\
\end{array}$ & 315.949 & 13.246 & $\begin{array}{c}0.208 \\
2.756 \\
0.767 \\
1.127 \\
2.334 \\
0.223 \\
12.605 \\
\end{array}$ & $\begin{array}{c}.001 * * \\
\\
.648 \\
.097 \\
.381 \\
.288 \\
.127 \\
.636 \\
<.001 * * \\
\end{array}$ & 66.4 \\
\hline $\begin{array}{c}\text { Step } 4 \\
\text { NEO-FFI } \\
\text { Openness } \\
\text { Conscientiousness } \\
\text { Extraversion } \\
\text { Agreeableness } \\
\text { Neuroticism } \\
\text { LOC } \\
\text { ALEKS } \\
\text { SAT Math } \\
\text { SAT Verbal }\end{array}$ & $\begin{array}{c}0.014 \\
-0.046 \\
0.023 \\
-0.027 \\
-0.023 \\
0.014 \\
-0.019 \\
-0.007 \\
0.002 \\
\end{array}$ & $\begin{array}{l}1.015 \\
0.955 \\
1.023 \\
0.973 \\
0.978 \\
1.014 \\
0.981 \\
0.993 \\
1.002\end{array}$ & 309.960 & 5.986 & $\begin{array}{l}0.295 \\
3.212 \\
0.722 \\
0.825 \\
2.070 \\
0.285 \\
5.504 \\
5.747 \\
0.864\end{array}$ & $\begin{array}{l}.050 * \\
.587 \\
.073 \\
.395 \\
.364 \\
.150 \\
.594 \\
.019 * \\
.017 * \\
.353\end{array}$ & 67.2 \\
\hline $\begin{array}{c}\text { Step 5 } \\
\text { NEO-FFI } \\
\text { Openness } \\
\text { Conscientiousness } \\
\text { Extraversion } \\
\text { Agreeableness } \\
\text { Neuroticism } \\
\text { LOC } \\
\text { ALEKS } \\
\text { SAT Math } \\
\text { SAT Verbal } \\
\text { HS GPA }\end{array}$ & $\begin{array}{c}0.010 \\
-0.049 \\
-0.014 \\
-0.019 \\
-0.018 \\
0.014 \\
-0.018 \\
-0.007 \\
0.003 \\
-1.272\end{array}$ & $\begin{array}{l}1.010 \\
0.952 \\
1.015 \\
0.981 \\
0.982 \\
1.014 \\
0.982 \\
0.993 \\
1.003 \\
0.298\end{array}$ & 301.358 & 8.601 & $\begin{array}{l}0.140 \\
3.532 \\
0.288 \\
0.396 \\
1.335 \\
0.262 \\
4.745 \\
5.409 \\
1.122 \\
8.149\end{array}$ & $\begin{array}{l}.003 * * \\
.708 \\
.060 \\
.591 \\
.529 \\
.248 \\
.609 \\
.029 * \\
.020 * \\
.290 \\
.004 * *\end{array}$ & 69.5 \\
\hline
\end{tabular}

Notes: Before the entry of any predictors, the cases being retained was $40.2 \%$ and non retained was $59.8 \%$.

NEO-FFI = NEO Five Factor Inventory; LOC = Nowicki-Duke Locus of Control Scale; ALEKS = Assessment and Learning in Knowledge Spaces; SAT = Scholastic Assessment Test; HS GPA = high school grade point average; $-2 \mathrm{LL}=-2 \log$ likelihood. $*=p<.05, * *=p<.01$ 


\section{Summary}

The final model fit the data significantly better and resulted in improved capability to predict student outcomes. The odds ratio is a common tool to explain this difference. For example, since the intercept only model is calibrated to benchmark the current data, if we continue to select students as we have and the population does not change, the odds that a randomly selected student will be classified correctly are $59.2 \% / 40.2 \%=1.45$. With the final model, our odds ratio is $69.5 \% / 30.5 \%=2.28$ for an overall improvement of $2.28 / 1.45=1.57$. The odds of a correct classification are 1.57 times higher with the final model compared to the intercept only model.

Predictors with significant unique effects included the aptitude measures as assessed by the ALEKS, MSAT and HSGPA (those scoring higher on these measures were more likely to be retained). While Conscientiousness was statistically significant at Block 1 and 2 entries, it failed to reach significance beginning with the Block 3 entry of the ALEKS scores. The reduction in the predictive value of Conscientiousness was due to it being redundant with ALEKS. While there was a statistically significant correlation between Conscientiousness and the ALEKS, $\mathrm{p}<$ 0.01, there was not a significant relationship between Conscientiousness and MSAT, VSAT or HSGPA. In essence, Block 3 entry of ALEKS was partially masking the effects of Conscientiousness.

No other affective characteristics, including LOC, were near significance with the exception of neuroticism. This characteristic is difficult to interpret as a potentially positive attribute but in general it was a significant model factor at $\mathrm{p}<0.127$ (87\% confidence) until step 5 in the model development. Considering positive traits such as attention to detail, this characteristic may be a contributor to retention.

Research suggests that scoring somewhat higher on neuroticism may not necessarily be negative in that it often results in these individuals being more cognitively attuned to making better choices in order to reduce distress. ${ }^{26}$ The means on neuroticism for the students participating in this study were higher than the general norms $(M=17.76)$ reported in $2006^{27}$ and those individuals who persisted in engineering were significantly higher than those who did not $(\mathrm{M}=$ 27.92 $\mathrm{SD}=12.19$ and $\mathrm{M}=24.09 \mathrm{SD}=10.29$, respectively). Statements on the subscale measuring neuroticism include items specific to worrying about things that could go wrong, feeling anxious, and feeling frustrated when dealing with minor annoyances. It may be that college students, who are more anxious about completing a task correctly and deal with stress by trying to come up with solutions, would also be more persistent in a field such as engineering where precision and dealing with complex problems are an everyday occurrence.

Relative to aptitude factors, they clearly dominated the affective factors in contributing to the prediction accuracy of the various model steps. MSAT, HSGPA, and ALEKS were consistently significant model predictors at a level $\mathrm{p}<0.05$ (95\% confidence or higher) throughout the steps.

The correlation data in Table 1 shows several potentially interesting relationships. As noted, there was a statistically significant correlation between Conscientiousness and the ALEKS math 
placement, $p<0.01$, suggesting overlap between these two measures. Finally, the affective characteristic of openness was strongly correlated with the other four NEO-FFI traits.

Our current study produced results similar to but different from our earlier study. ${ }^{15}$

- Relative to aptitude measures: Our original study found the most significant predictor of GPA was HSGPA and SAT scores were not significant. This study also identified HSGPA but added MSAT and ALEKS as important predictors also. We did not use ALEKS during the period covered by our original study.

- Relative to affective factors, our original study found conscientiousness and LOC as significant predictors. This study also identified conscientiousness as important but did not find LOC as a significant predictor.

In understanding these differences, it is important to note that our first study examined the students in the program over the first several years of operation. Consequently we had a small sample which we could use across the various tests $(n=27)$. This current study includes a significant increase in the sample size $(n=277)$ and a longer period of time over which we were able to study trends. Thus we believe its results are more representative of our students.

As we continue to track the final results of the students in our study, it is clear that there are several action items. First, we should consider ways to build awareness of and capability in the traits related to conscientiousness into the freshman engineering course sequence. Second, we need to further explore how we can understand the aptitude factors at the time of application. In particular the combination of HSGPA and MSAT along with potential indicators of conscientiousness may have potential. This is a two edged sword since our full model, including information gathered after students are admitted, only improved our ability to predict success by $20 \%$ from a random coin flip (50/50). Since one of our mission elements is access, we must continually be wary of failing to admit potentially successful students.

\section{Bibliography}

1. Marra, R., Rodgers, K., Shen, D., and Bogue, B. "Leaving Engineering: A Multi-Year Single Institution Study." Journal of Engineering Education, Vol. 101, 2012, pp. 6-27.

2. Ohland, M., Sheppard, S. D., Lichtenstein, G., Eris, O., Chachra, D., \& Layton, R., "Persistence, engagement, and migration in engineering programs." Journal of Engineering Education, Vol. 97, 2008, pp. 259-278.

3. Takahira, S., Goodings, D., and Byrnes, B., "Retention and Performance of Male and Female Engineering Students: An Examination of Academic and Environmental Variables," Journal of Engineering Education, Vol. 88, 1998, pp. 297-304.

4. Ohland, Matthew W., Sharon A. Frillaman, Guili Zhang, Catherine E. Brawner, and Thomas K. Miller. "The Effect of an Entrepreneurship Program on GPA and Retention." Journal of Engineering Education, Oct. 2004, pp. 293-301.

5. Lackey, L., Lackey, W., Grady, H., Davis, M., "Efficacy of Using a Single, Non-Technical Variable to Predict the Academic Success of Freshmen Engineering Students," Journal of Engineering Education, 2003, Vol. 92, pp. 41-48.

6. French, B., Immekus, J., and Oakes, W., “An Examination of Indicators of Engineering Students' Success and Persistence," Journal of Engineering Education, 2005, pp.419-422. 
7. Zhang, G., Anderson, T.J., Ohland, M.W., and Thorndyke, B.R., "Identifying Factors Influencing Engineering Student Graduation: A Longitudinal and Cross-Institutional Study," Journal of Engineering Education, Vol. 93, 2004, pp. 313-320.

8. Lam, P., Doverspike, D., Mawasha, R., "Predicting Success In A Minority Engineering Program," Journal Of Engineering Education, Vol. 88, 1999, pp. 256-267.

9. Kanoy, K. W., Wester, J. L., and Latta. M. Predicting college success of freshmen using traditional, cognitive, and psychological measures. Journal of Research Development in Education, 22(3), 1989, pp.65-70.

10. Bernhold, L., Spurlin J., and Anson C. Understanding Our Students: A Longitudinal-Study of Success and Failure in Engineering with Implications for Increased Retention, Journal of Engineering Education, July 2007, pp. 263-274.

11. Hall, C. W., Smith, K., \& Chia, R. Cognitive and Personality Factors in Relation to Timely Completion of a College Degree. College Student Journal, 42 (4), 2008, 1087-1098.

12. Borkowski, J. G., Carr, M., Rellinger, L., and Pressley, M. Self-regulated Cognition: Interdependence of Megacognition, Attributions, and Self-esteem. In B. Jones \& L. Idol (Eds.), Dimensions of Thinking and Cognitive Instruction. Hillsdale, NJ: Lawrence Erlbaum Associates, Inc., 1990, pp. 53-92.

13. Borkowski, J. G., Chan, L. K. S., \& Muthukrishna, N. "A Process Oriented Model of Metacognition: Links between Motivation and Executive Functioning." In G. Schraw \& J. Impara (Eds.), Issues in the Measurement of Metacognition. Buros Institute of Mental Measurements, University of Nebraska, Lincoln, NE., 2000, pp. 142.

14. Kauffmann, P., Abdel-Salam T., and Garner, J. "Predictors of Success in the First Two Years- A Tool for Retention." Proceedings of the American Society of Engineering Education Annual Conference, Honolulu, June 2007.

15. Kauffmann, P., Hall, C., Dixon E. and Garner, J. "Predicting Academic Success for First Semester Engineering Students Using Personality Trait Indicators. Proceedings of the American Society of Engineering Education Annual Conference, Pittsburgh, June 2008.

16. Goldberg, L. R. "The Structure of Phenotypic Personality Traits." American Psychologist, 48, 1993, pp., 2634.

17. Srivastava, S. "Measuring the Big Five Personality Factors." Retrieved December 15, 2007 from http://www.uoregon.edu/ sanjay/bigfive.html.

18. Rotter, J. B. "Generalized expectancies for internal versus external control of reinforcement." Psychological Monographs, 80, 1966, whole issue.

19. Nowicki, S. \& Strickland, B. "Nowicki-Strickland Internal-External Locus of Control Scale." Available from Dr. Stephen Nowicki, Psychology Department, Emory University, Atlanta, GA 30322.

20. ALEKS, http://www.aleks.com/

21. McCrae, R., Costa, P., and Busch, C. "Evaluating Comprehensiveness in Personality Systems: The California Q-set and the Five-factor Model." Journal of Personality, 54, 1986, pp.430-446.

22. Cech, S. J. "SAT scores for Class of 2008 halt slide of recent years." Education Week. August 26, 2008, $28,7$.

23. Frey, M., and Detterman, D. "Scholastic Assessment of The relationship Between the Scholastic Assessment Test and General Cognitive Ability." Psychological Science, 15, 2004, pp.373-378.

24. Nowicki, S., and Duke, M. "The association of Children's Nonverbal Decoding Abilities with Their Popularity, Locus of Control, and Academic Achievement." Journal of Genetic Psychology, 153, 1992, 385-393.

25. Costa, P., and McCrae, R. "Normal personality inventories in clinical assessment: General requirements and potential for using the NEO Personality Inventory.” Psychological Assessment, 4, 1992, pp. 20-22.

26. Tamir, M., Robinson, M. D., \& Solberg, E. C. (2006). "You may worry, but can you recognize threats when you see them? Neuroticism, threat identifications, and negative affect.". Journal of Personality, 2006, Vol. 74, pp. 1482-1505.

27. Terraciano, A. Costa P., McCrae, R. "Personality Plasticity after Age 30." Personality and Social Psychology Bulletin, 2006, Vol. 32, pp. 999-1009. 